\title{
PROSES KELEMBAGAAN DAN PERATURAN PEMERINTAH PADA LEMBAGA AMIL ZAKATI)
}

\author{
Bonita Almira Putri \\ Mahasiswa Program Studi S1 Ekonomi Islam Fakultas Ekonomi dan Bisnis Universitas Airlangga \\ Email: bonita.almira.putri-12@feb.unair.ac.id \\ Raditya Sukmana \\ Departemen Ekonomi Syariah Fakultas Ekonomi dan Bisnis Universitas Airlangga \\ Email: raditya-s@feb.unair.ac.id
}

\begin{abstract}
This study is aimed to shows and identification of Amil Zakah Institution responses about management of zakah rules by governance in strategic responses to institutional processes views. The researcher also want to see the LAZ perspectives about the changes of the regulations which is being problem for the past a year in Indonesia. Research approch is qualitative approach explanatory. Data collection interviews with the informants in case study object. Object of this research is LAZ YDSF Surabaya because they are the oldest in East Java Province and is founded in Surabaya. Technique analysis is using descriptive narrative and pairing pattern. This research shows that LAZ YDSF is not include in acquiesce response, because there are some regulations that needed to be compromised with the government. Purpose of this research is want to see a new perspective from Amil Zakah Institutions in Indonesia in order to make the best coordination and sinergisity with government to build a better country.
\end{abstract}

\section{Key Words: Zakat, UU Zakat, LAZNAS, LAZ Strategic Responses, Institutional Theory}

\section{Pendahuluan}

Zakat adalah ibadah yang memiliki peranan penting dalam segi ekonomi, sosial, budaya, serta agama yang berguna untuk mensejahterakan masyarakat. Dalam penerapannya, zakat telah banyak berkontribusi banyak terhadap penerimaan negara, terutama pada negara Islam dan negara yang memiliki dominan penduduk Islam. Ada beberapa negara Islam yang menggunakan filantropi tersebut sebagai pajak. Berbeda dengan negara Indonesia yang bukan dari latar belakang negara Islam. UU Zakat yaitu pada tahun 1999 mengalami perkembangan yang bagus, apalagi setelah reformasi. Menurut Fauzia (2013:200), reformasi Indonesia menjadi suatu alasan dibalik para pejuang Muslim melakukan perubahan kebijakan dan praktek manajemen zakat di Indonesia ke arah yang lebih baik.

Menurut penelitian Rosyidah dan Manzilati. (2014:), realitas tanggapan LAZ dan muzaki pasca perubahan UU tentang pengelolaan zakat adalah menghambat kinerja LAZ karena LAZ tidak diberi kesempatan untuk langsung dengan mudah melakukan pendistribusian seperti sebelumnya. Hal tersebut dikhawatirkan memiliki dampak memperlambat proses distribusi ke mustahik.

Dengan hal tersebut, dapat disimpulkan rumusan masalah yaitu bagaimana respon LAZ pasca adanya PP No 14 Tahun 2014 tentang pengelolaan zakat? Penelitian ini ditinjau dari teori 
Putri, et al/ Jurnal Ekonomi Syariah Teori dan Terapan Vol. 5 No. 2 Februari 2018: 135-143;

\section{PROSES KELEMBAGAAN DAN PERATURAN PEMERINTAH PADA LEMBAGA AMIL ZAKAT}

kelembagaan yang diterbitkan oleh Oliver

(1991) dengan memakai indikator organisasi melakukan pasif menerima suatu tekanan. Penelitian ini dilakukan pada LAZ yang tertua di Jawa Timur dan berpusat di Surabaya, yaitu Yayasan Dana Sosial Al Falah (YDSF).

\section{Landasan Teori}

Disebutkan oleh Qardhawi (2005:20-87), fungsi Zakat berperan sebagai pengentas kemiskinan.

Potensi Zakat

Menurut survey yang dilakukan oleh Asia Pacific Philanthrophy Consortium (APPC) pada 2001, Indonesia sebagai negara paling tinggi se-dunia untuk mengeluarkan donasi dari harta kekayaannya dengan faktor keagamaan (Fauzia, 2008:1). Potensi yang sangat besar apabila segala aspek atau pihakpihak terkait bersama membangun sinergi dengan baik seperti dengan membuat dan menjalankan kebijakan dengan bijaksana. Menurut Politik ZISWAF pada Huda (2012: 107), "Mengentas 100 kelvarga miskin adalah dengan CSR, namun jika mengentaskan sejuta orang miskin itu namanya adalah kebijakan." Persoalan di Indonesia masih menjadi persoalan yang sangat kompleks dari segi sumber daya manusia maupun manajemennya. Pengembangan pelatihan-pelatihan serta riset-riset di bidang ekonomi dan keuangan syariah merupakan hal yang perlu dilakukan saat ini. Pada intinya, perlu pemahaman mendalam, kerja keras, serta kerja ikhlas dalam mengentas kemiskinan melalui filantropi zakat dengan membangun sinergi yang baik antar pelakunya. (Beik dan Arsyianti, 2016: 159)

\section{Peran BAZNAS dan LAZ}

BAZNAS diberikan wewenang sebagai pengelola zakat nasional, sekaligus yang berhak memverifikasi berdirinya LAZ. Dengan wewenang BAZNAS tersebut, pengumpulan dana zakat diharapkan bisa terorganisir secara efektif, dan dapat terdistribusikan secara efisien. Badan Amil Zakat menjadi titik paling penting dalam upaya pengentasan kemiskinan, manajemen yang baik dalam pengelolannya dan amilin (sumber daya manusia) yang ada dalam sebuah Badan Amil Zakat harus menguasai bidangnya masing dengan displin ilmu yang tepat.

Teori Kelembagaan

Teori kelembagaan adalah teori yang membahas soal perilaku maupun peraturan-peraturan yang ada dalam suatu sekumpulan organisasi dalam satu kesatuan lembaga. Menurut Oliver (1991:146), kelembagaan adalah teori yang membahas nilai, norma, dan perilaku dalam satu kesatuan lembaga atau organisasi atau institusi. Institusi atau organisasi menurut Scott dalam Oliver (1991:147), menjelaskan bahwa institusi yang dimaksud disini adalah seperti agen pemerintah, hukum, struktur regulasi, profesi dan keadilan. Segala yang ada di masyarakat pasti memiliki institusi yang 
Putri, et al/ Jurnal Ekonomi Syariah Teori dan Terapan Vol. 5 No. 2 Februari 2018: 135-143;

PROSES KELEMBAGAAN DAN PERATURAN PEMERINTAH PADA LEMBAGA AMIL ZAKAT

berbeda aspek namun tetap saling berkaitan. Dengan menggunakan sudut

\section{Pasif Menerima Suatu Perubahan}

\begin{tabular}{|l|l|l|l|}
\hline & Legistimasi & Efisiensi & Keberagaman \\
\hline Organisasi & Tinggi & Tinggi & Rendah \\
\hline
\end{tabular}

Sumber: Strategic Responses to Institutional Processes,

Oliver $(1991,160)$

pandang kelembagaan dapat mengidentifikasikan berbagai tantangan dari berbagai aspek juga, yaitu aspek sosial, ekonomi, politik, hukum, dan budaya.

Strategic Responses to Institutional

Processes dan Indikatornya

Oliver (1991:152) menjelaskan beberapa respon stratejik suatu organisasi dalam menanggapi suatu perubahan atau proses kelembagaan yang ada. Menurutnya, kelembagaan berfokus pada aspek sosial dan kultural pada lingkungan organisasi. Berikut ilustrasi gambar dari tipe respon stratejik suatu organisasi dalam menanggapi tekanan yang ada dalam kelembagaan:

Pasif menerima disini, bukan berarti tidak melakukan apa-apa yang menyebabkan organisasi akan mati. Dalam Oliver (1991:145), justru menjelaskan bahwa semua tergantung pada objek dan lingkungan itu sendiri. Sehingga saat melihat contoh kasus yang dialami oleh organisasi masyarakat LAZNAS, dimana tujuannya sama dengan pemerintah, maka pasif menerima suatu tekanan adalah pilihan yang bijak, karena antar keduanya dibutuhkan sinergi dan dukungan satu sama lain.

\section{Metode Penelitian}

\section{Pendekatan Penelitian}

Penelitian ini menggunakan pendekatan penelitian kualitatif preposisi teoritisf, karena dalam permasalahan yang dihadapi dalam penelitian ini membutuhkan penjelasan mendalam soal hubungan manusia dalam suatu organisasi. Oleh sebab itu juga, pendekakatan studi kasus dipilih dalam penelitian ini.

\section{Ruang Lingkup penelitian}

Penelitian ini memfokuskan pembahasan pada respon LAZ yang akan dikaji berdasarkan perspektif strategic responses to institutional processes, yaitu melihat dari perizinan, mekanisme organisasi, pelaporan keuangan, serta sanksi yang dilakukan BAZNAS pada LAZ. Sehingga, nantinya akan menunjukan suatu LAZ yang diteliti tersebut apakah pasif menerima.

\section{Jenis dan Sumber Data}

Penelitian ini didapat dari data primer dan sekunder. Informan yang dipilih dalam penelitian ini adalah seperti dijelaskan diatas yaitu kepala cabang, kepala divisi keuangan dan operasional, dan kepala divisi komunikasi dan sumberdaya manusia. 
Putri, et al/ Jurnal Ekonomi Syariah Teori dan Terapan Vol. 5 No. 2 Februari 2018: 135-143;

PROSES KELEMBAGAAN DAN PERATURAN PEMERINTAH PADA LEMBAGA AMIL ZAKAT

Prosedur Pengumpulan Data

Prosedur pengumpulan data dalam penelitian ini mengacu pada prinsip yang dimiliki oleh Yin (2014:103) yaitu berfokus pada enam sumber bukti, sebagai berikut: Dokumentasi, Rekaman arsip, Wawancara Teknik Analisis

Strategi umum yang disarankan oleh Yin (2014:136) dan digunakan oleh peneliti dalam penelitian ini guna untuk mendapatkan hasil yang maksimal adalah dengan mendasarkan pada preposisi teoritis. Strategi yang menuntun studi kasus dengan akurat. Teknik pemeriksaan adsalah penjodohan pola.

\section{Analisis}

Analisis Bab VII, terdapat 4 bagian, yaitu persyaratan organisasi, mekanisme perizinan, pembentukan perwakilan LAZ, dan amil zakat atau perkumpulan orang dalam masyarakat

Walau proses perizinan lama dan agak susah karena sempat ganti kepengurusan, namun LAZ tetap bersikeras mendapat pengakuan hukum agar tetap dipercaya oleh masyarakat dan pemerintah itu sendiri. Persyaratan organisasi dilaksanakan dengan baik, seperti membentuk YDSF Forum untuk memperkuat jalinan antar YDSF pusat dan wilayah. Hal tersebut memang harus dilakukan dalam suatu kelembagaan demi terciptanya koordinasi yang baik sehingga minim miss komunikasi. YDSF murni dari masyarakat untuk masyarakat, dimana terdapat struktur organisasi yang teratur.

Setelah pemaparan diatas, dapat menyimpulkan bahwa LAZ YDSF dalam penerapan Bab VII pada PP No 14 Tahun 2014 adalah tinggi. Maksudnya adalah suatu organisasi dalam kelembagaan yang berhubungan dengan banyak pihak, membuat LAZ membutuhkan dukungan moril maupun materil, termasuk pengakuan tertulis dari hukum pemerintah, demi terciptanya tujuan yang sama.

Analisis Bab IX, yaitu pelaporan dan pertanggungjawaban keuangan LAZ pada BAZNAS

Mematuhi pelaporan audit syar tiap bbulan atau setaun sekali, walau agak beban untuk mengumpulkan target 50 Milyar pertahun. Pelaporan data muzaki agak terasa berat, kurang efisien, karena data muzaki yang tersebar membuat jumlah dana tidak sepenuhnya masuk YDSF. Akad harus jelas melihat pekerjaan halal, sedangkan itu tidak bisa memaksimalkan waktu dan jumlah donatur YDSF, karena banyak donatur tanpa nama. Donatur harus bekerja halal, kurang sopan sehingga tidak maksimal menarik donatur, karena pekerjaan bukan laz yang mengatur.

Setelah pemaparan diatas, dapat menyimpulkan bahwa LAZ YDSF dalam penerapan Bab IX pada PP No 14 Tahun 
Putri, et al/ Jurnal Ekonomi Syariah Teori dan Terapan Vol. 5 No. 2 Februari 2018: 135-143;

\section{PROSES KELEMBAGAAN DAN PERATURAN PEMERINTAH PADA LEMBAGA AMIL ZAKAT}

2014 yaitu rendah. Hal tersebut dikarenakan adanya sedikit pertimbangan yang menyulitkan LAZ YDSF untuk $100 \%$ menerima peraturan pelaporan keuangan menurut BAZNAS.

\section{Analisis Bab X, yaitu sanksi administratif}

Setelah pemaparan diatas, peneliti dapat menyimpulkan, bahwa LAZ YDSF dalam penerapan Bab X pada PP No 14 Tahun 2014 yaitu tinggi. Hubungan dengan pihak lain saling ketergantungan karena banyaknya stakeholder, dan hal tersebut membuat YDSF memiliki banyak pilihan keputusan dalam menghadapi masalah agar tidak menimbulkan ketidakadilan disatu pihak. Hal tersebut bukan hal negatif, selama LAZ tetap dapat melayani masyarakat.

\section{Analisis Strategic Responses to Institutional} Processes

Setelah pemaparan ketiga sub bab diatas, dapat ditarik beberapa kesimpulan respon yang dimiliki oleh LAZ pasca PP No 14 Tahun 2014. Organisasi yang mendapat intervensi dari pemerintah, dalam konteks kelembagaan, termasuk proses yang wajar karena selama memiliki satu tujuan yang sama, semua pihak terkait memang sudah segaimana mestinya memiliki sinergi yang kuat.

Dalam penelitian ini, respon LAZ terhadap Undang-Undang pemerintah ini, memiliki jenis respon yang pasif menerima atau mengadopsi aturan, namun

memerlukan adanya kompromi. Sehingga, jika dilihat dari kacamata strategic responses, peneliti mengidentifikasi bahwa LAZ tidak termasuk dalam kategori pasif menerima. Beberapa penjelasan dapat dilihat khususnya dari segi pelaporan keuangan yang terdapat adanya harapan LAZ untuk berkompromi menyangkut pelaporan data muzaki LAZ dan hubungan yang terjalin dan ketergantungan dengan banyak stakeholder.

\section{Kesimpulan}

Dari hasil pembahasan di atas, terdapat beberapa kesimpulan mengenai penerapan PP No 14 tahun 2014 tentang pengelolaan zakat pada LAZ YDSF. Kesimpulan tersebut diantaranya adalah :

1. Diantara beberapa peraturan yang ada didalam PP No 14 Tahun 2014 tentang pengelolaan zakat, LAZ YDSF tidak ada masalah signifikan yang dialami dan selama ini telah menjalankan sebaik mungkin. Perizinan menteri dan mekanisme pembentukan organisasi yang baik, pelaporan yang amanah, serta tidak pernah melakukan pelanggaran atau sanksi. Walau tidak ada masalah dan LAZ YDSF telah menjalankan dengan baik, namun LAZ YDSF tidak termasuk organisasi yang melakukan $100 \%$ pasif menerima suatu tekanan dan termasuk 
Putri, et al/ Jurnal Ekonomi Syariah Teori dan Terapan Vol. 5 No. 2 Februari 2018: 135-143;

PROSES KELEMBAGAAN DAN PERATURAN PEMERINTAH PADA LEMBAGA AMIL ZAKAT

yang mengharapkan adanya kompromi.

2. Terdapat beberapa indikator yang tidak sesuai dengan keadaan lapangan. Hal tersebut dikarenakan peneliti menemukan adanya respon dari para informan yang sedikit mengeluh terkait pelaporan data muzaki ke BAZNAS. Serta peneliti juga menemukan adanya ketergantungan yang tinggi dengan para stakeholder, sehingga LAZ YDSF akhirnya mempunyai beragam pilihan keputusan agar tetap menjaga keterikatan tersebut. Alhasil, LAZ YDSF memiliki tingkat legistmasi yang tinggi, efisiensi yang rendah, dan keberagaman yang tinggi. Dimana syarat tersebut tidak menunjukan respon pasif menerima.

3. Peneliti menemukan fakta di lapangan bahwa audit syariah yang terdapat pada PP No 14 tahun 2014 belum dipraktikan oleh BAZNAS pada LAZ. Ada juga peraturan yang akan diluncurkan dalam waktu dekat yang berhubungan dengan Dirjen Pajak, yaitu muzaki mendapat kwitansi telah membayar zakat, yang nantinya dapat mengurangi beban pajak muzaki tersebut.
Setelah menarik kesimpulan, peneliti dapat mengelompokan beberapa saran, yaitu diantaranya:

1. Untuk Pemerintah

a. Melakukan kajian lebih mendalam untuk sistem penghimpunan agar semuapihak merasa adil. Misalnya saja dalam penginput-an data muzaki sebaiknya tidak perlu. Jika niatnya ingin mengarahkan muzaki agar terpusat pada satu LAZ saja, maka membuat peraturan bukan pada LAZ, namun untuk masyarakat luas. Pemerintah dapat mensosialisasikan lewat media, lewat seminar ke lembaga dan perusahaanperusahaan yang ada di Indonesia.

b. Saat pergantian Kementerian, tidak perlu menharuskan suatu lembaga untuk mengulang lagi persyaratan izin kelembagaan tersebut. Lebih baik diverifikasi ulang saja dengan menyebutkan nomor SK sebelumnya.

c. Untuk pendistribusian agar tidak terjadi Overlapping, diberikan nomor ID atau kartu identitas data penerima agar otomatis 
Putri, et al/ Jurnal Ekonomi Syariah Teori dan Terapan Vol. 5 No. 2 Februari 2018: 135-143;

PROSES KELEMBAGAAN DAN PERATURAN PEMERINTAH PADA LEMBAGA AMIL ZAKAT

dapat terdeteksi sudah

wawancara,

namun

masuk ranah LAZ yang

ditambah

dengan

mana.

2. Untuk LAZNAS

a. Tetap menjaga hubungan, koordinasi, dan kepercayaan yang baik dengan BAZNAS dan pihak terkait lain.

b. Saat melakukan rapat koordinasi beberapa bulan sekali dengan YDSF Forum, lebih baik mengajak perwakilan koordinator dari BAZNAS, sehingga rapatnya bisa terintegrasi dengan efisien.

c. Adanya pemasangan target pribadi untuk pengumpulan pendapatan yang melebihi target dari BAZNAS, sehingga dapat mempengaruhi alam bawah sadar saat bekerja dengan tulus.

d. Memaksimalkan program bantuan dan pemberdayaan yang ada untuk masyarakat. Karena pada dasarnya LAZ adalah untuk melakukan dua program tersebut, dimana sesuai dengan Baznas.

3. Untuk Penelitian Selanjutnya

a. Memakai pendekatan yang sama yaitu kualitatif studi kasus, dan strategi triangulasi sumber yang membutuhkan adanya respon BAZNAS juga.

b. Menjelaskan lebih spesifik terkait sudut pandang kelembagaan.

4. Untuk Praktisi Ekonomi Islam

a. Lebih mempercayai lembaga-lembaga Keuangan Syariah, baik pemerintah maupun nonpemerintah.

b. Lebih bersemangat lagi dalam menjadi seorang yang sanggup membayar zakat, sehingga roda perekonomian dapat lebih cepat berputar, dan pihak BAZNAS dan LAZNAS juga dapat bekerja lebih optimal.

c. Berusaha selalu sosialisasikan pentingnya Keuangan Syariah pada masyarakat luas, salah satunya memprioritaskan lembaga-lembaga tersebut dalam transaksi dan mengajak relasi untuk mempercayai pentingnya berekonomi syariah.

d. Sebisa mungkin berkontribusi, misal berkeinginan untuk membuat kebijakan yang 
Putri, et al/ Jurnal Ekonomi Syariah Teori dan Terapan Vol. 5 No. 2 Februari 2018: 135-143;

PROSES KELEMBAGAAN DAN PERATURAN PEMERINTAH PADA LEMBAGA AMIL ZAKAT

nantinya dapat membantu

terjalinnya kerjasama yang

kuat dalam Keuangan

Syariah.

e. Menjaga sinergi dengan sebanyak-banyaknya manusia, khususnya yang se-visi dan misi dalam bermanfaat bagi sesama.

5. Untuk Akademisi Ekonomi Islam

a. Mengkaji ilmu-ilmu Ekonomi Islam yang lebih luas, mendalaminya, dan mensosialisasikan

pendidikan hal tersebut di tempat-tempat seluas mungkin.

b. Mempraktekan ilmu tersebut di kehidupan nyata.

c. Menjaga sinergi dengan sebanyak-banyaknya manusia, khususnya yang se-visi dan misi dalam bermanfaat bagi sesama.

\section{Daftar Pustaka}

Beik, Irfan Syauqi dan Laily Dwi. 2016. Ekonomi Pembangunan Syariah. Edisi Revisi. Depok: PT Rajagrafindo Persada.

Creswell, John. W. 2015. Research Design Second Edition. Terjemahan oleh Lintan Lazuardi. Yogyakarta: Pustaka Pelajar.

Dawson, Yelena. 2015. The Institutionalisation of Private Sector Performance Masurement in an Australian Oot-forprofit Organisation._epublications@scu.
Fakultas Bisnis Administrasi. Southern Cross University.

Fauzia, Amelia. 2008. Faith and a State: a History of Islamic Philanthropy in Indonesia. Disertasi tidak diterbitkan. Melbourne Faculty of Arts University of Melbourne.

Hilmi, Hasbullah. 2012. Dinamika Pengelolaan Wakaf Uang: Studi Sosio-Legal Perilaku Pengelolaan Wakaf Uang Pasca Pemberlakuan UU No. 41 Tahun 2004 Tentang Wakaf. ljtihad, Jurnal Wacana Hukum Islam dan Kemanusiaan, Vol. 12, No. 2 (12).

Huda, Nurul, dkk. 2012. Kebijakan Publik Islami. Jakarta: Kencana Prenada Media Group.

Kamil, Syukron. 2016. Ekonomi Islam, Kelembagaan, dan Konteks Keindonesiaan. Depok: PT Rajagrafindo Persada.

Karim, Adiwarman Azwar. 2010. Sejarah Pemikiran Ekonomi Islam. Edisi Ketiga. Jakarta: Rajawali Press.

Khairinisa, Dini. 2012. Proses Konstruksi Perkembangan Organisasi Zakat (Studi pada Dompet Dhuafa Republika). Jakarta: UI Library.

LAZ YDSF,. Profil LAZ, (Online),

(www.ydsf.org 20 November 2016. (20.17)

Muhammad, dan Abu Bakar. 2011.

Manajemen Organisasi Zakat. Malang:

Madani Wisma Kalimetro.

Modell, S. (2001). Performance Measurement and Institutional Processes: A Study of Managerial Responses to Public Sector 
Putri, et al/ Jurnal Ekonomi Syariah Teori dan Terapan Vol. 5 No. 2 Februari 2018: 135-143;

\section{PROSES KELEMBAGAAN DAN PERATURAN PEMERINTAH PADA LEMBAGA AMIL ZAKAT}

Reform. Management Accounting Research, 12: 439, 441.

Nafik, Muhammad dan Hazami Bashlul. 2016. Peran dan Implementasi Wakaf dalam Peningkatan Kesejahteraan Masyarakat. Inferensi Junral Penelitian Sosial dan Keagamaan. Vol 10 No.1:

Oates, Grainne. 2013. Exploring the Links between Stakeholder Type, and Strategic Response to Stakeholder and Institutional Demands in the Public Sector Context. International Journal of Business and Management; Vol. 8, No. 21:51-52.

Oliver, C. (1991). Strategic Responses to Institutional Processes. Academy of Management Review Journal, 16, 146-163. Qardhawi, Yusuf. 1996. Hukum Zakat. Bogor: Pustaka Lintera Antar Nusa.

Qardhawi, Yusuf. 2005. Spektrum Zakat dalam Membangun Ekonomi Kerakyatan. Jakarta: Zaikrul Hakim.

Republik Indonesia. Undang-Undang No 38 Tahun 1999 tentang Pengelolaan Zakat. 1999: Kementerian Agama.

Tahun 2011 tentang Pengelolaan Zakat. 2011 : Diperbanyak oleh BAZNAS. PP No 14 Tahun 2014 tentang Penjelasan UU No 23 Tahun 2011 Pengelolaan Zakat. 2014: Diperbanyak oleh BAZNAS.

Romanelli, Elaine. The New Instituitonalism in Organizational Analysis by Powell and Dimaggio Review. The Academy of Management Review Journal, Vol. 17, No. 3 (Jul., 1992), 612-614.
Rosyidah, Trie A dan Asfi Manzilati. 2014. Implementasi Undang-Undang Nomor 23 Tahun 2011 terhadap Legalitas Pengelolaan Zakat oleh Lembaga Amil Zakat (Studi pada Beberapa LAZ di Kota Malang). Malang: Universitas Brawijaya). UB.

Sudarwati, Yuni dan Nidya Waras Sayekti. 2011. Jurnal Ekonomi \& Kebijakan Publik, Vol. 2, No. 1, (Juli): 578-581

Wahyuni, Ersa Tri. 2013. The Role of Entrepreneur in IFRS Diffusion: The Case Study of Convergence IFRS in Indonesia.

Yin, Robert K. 2014. Case Study Research: Design and Method. Terjemahan oleh $M$. Djauzi Mudzakir. Jakarta: PT Rajagrafindo Persada.

Yustika, Ahmad Erani. 2013. Ekonomi Kelembagaan. Paradigma, Teori, dan Kebijakan. Jakarta: Penerbit Airlangga. 